\title{
A prospective study of the motivational and health dynamics of Internet Gaming Disorder
}

\author{
Netta Weinstein ${ }^{\text {Corresp., }}{ }^{1}$, Andrew K Przybylski ${ }^{2,3}$, Kou Murayamaa ${ }^{4,5}$ \\ ${ }^{1}$ School of Psychology, Cardiff University, United Kingdom \\ 2 Oxford Internet Institute, University of Oxford, United Kingdom \\ 3 Department of Experimental Psychology, University of Oxford, United Kingdom \\ 4 School of Psychology and Clinical Language Sciences, University of Reading, United Kingdom \\ 5 Kochi University of Technology, Japan \\ Corresponding Author: Netta Weinstein \\ Email address: weinsteinn@cardiff.ac.uk
}

The American Psychiatric Association has identified Internet Gaming Disorder (IGD) as a potential psychiatric condition and called for research to investigate its etiology, stability, and impacts on health and behavior. The present study recruited 5,777 American adults and applied self-determination theory to examine how motivational factors influence, and are influenced by, IGD and health across a six month period. Following a preregistered analysis plan, results confirmed our hypotheses that IGD criteria are moderately stable and that they and basic psychological need satisfaction have a reciprocal relationship over time. Results also showed need satisfaction promoted health and served as a protective factor against IGD. Contrary to what was hypothesized, results provided no evidence directly linking IGD to health over time. Exploratory analyses suggested that IGD may have indirect effects on health by way of its impact on basic needs. Implications are discussed in terms of existing gaming addiction and motivational frameworks. 


\author{
Netta Weinstein ${ }^{1}$ \\ ${ }^{1}$ School of Psychology \\ ${ }^{1}$ Cardiff University
}

10

Andrew K. Przybylski²,3

12

${ }^{2}$ Oxford Internet Institute

21 Correspondence concerning this article should be addressed to Netta Weinstein, School of

22 Psychology, Cardiff University, Cardiff, United Kingdom

23 Contact: weinsteinn@cardiff.ac.uk 
The American Psychiatric Association has identified Internet Gaming Disorder (IGD) as a

28 potential psychiatric condition and called for research to investigate its etiology, stability, and

29 impacts on health and behavior. The present study recruited 5,777 American adults and applied

30 self-determination theory to examine how motivational factors influence, and are influenced by,

31 IGD and health across a six month period. Following a preregistered analysis plan, results

32 confirmed our hypotheses that IGD criteria are moderately stable and that they and basic

33 psychological need satisfaction have a reciprocal relationship over time. Results also showed

34 need satisfaction promoted health and served as a protective factor against IGD. Contrary to

35 what was hypothesized, results provided no evidence directly linking IGD to health over time.

36 Exploratory analyses suggested that IGD may have indirect effects on health by way of its

37 impact on basic needs. Implications are discussed in terms of existing gaming addiction and

38 motivational frameworks.

39

40

41 


\section{Introduction}

Internet-based video games are a ubiquitous form of recreation pursued by the majority

of adults and young people (Duggan, 2015a). With sales eclipsing box office receipts, games are now an integral, even inescapable, part of modern leisure (MPAA, 2015; Newzoo, 2016).

Commensurate with their popularity, concerns that games dysregulate the behavior of some have immerged (Kardefelt-Winther, 2014b). The widespread appeal of these virtual contexts has been of particular interest to psychologists and psychiatrists (for a review see King, Haagsma, Delfabbro, Gradisar, \& Griffiths, 2013). In fact, the most recent revision of the Diagnostic and Statistical Manual of Mental Disorders (DSM-5; American Psychiatric Association, 2013) identifies Internet Gaming Disorder (IGD) as a possible psychiatric condition. Following this determination, the American Psychiatric Association's (APA) Substance-Related Disorders Work Group outlined a call for rigorous research into the potential disorder's validity, etiology, and temporal stability (Hasin et al., 2013).

Because research responding to this call for a better understanding of IGD is at a formative stage, there are active debates surrounding the construct's conceptual scope and measurement approaches (Griffiths et al., 2016; Kardefelt-Winther, 2014b; Petry et al., 2014). Some argue for a theoretical framing akin to a substance abuse disorder (e.g. Petry et al., 2014), wherein gaming is, in itself, inherently addictive, whereas other scholars frame Internet-based gaming as a self-regulatory challenge (e.g., Griffiths et al., 2016; Kardefelt-Winther, 2014). The state of the art work in this area suggests links with social behaviors and life satisfaction, but does not differentiate between online and offline games (e.g. Festl, Scharkow, \& Quandt, 2013), adequately distinguish between passionate and pathological engagement (for a review see, Ferguson, Coulson, \& Barnett, 2011). Though ongoing research has examined the prevalence of 
65 individual criteria in line with APA guidance, it has not bridged the self-regulation and addiction

66 literatures (see Przybylski, 2016; Przybylski, Weinstein, \& Murayama, 2016b). In addition,

67 though this body of work offers some evidence that IGD-type symptoms may link with social

68 and mental health (e.g., Festl et al., 2013), there is very little longitudinal evidence exploring

69 antecedents and consequences of IGD symptoms (for an exception see Scharkow, Festl, \&

70 Quandt, 2014). The aim of the present research is to directly address this gap by linking self-

71 regulation and Internet Gaming Disorder research. Our goal is to directly examine how

72 problematic gaming emerges from a state of dysregulation, and how it predicts health.

\section{Gaming and Health}

To this end we build on a growing literature that suggests there is a basis to expect excessive or problematic gaming may be related to lower health, though findings in this area are mixed. There is some evidence that video gaming can promote healthy behaviors (Baranowski, Buday, Thompson, \& Baranowski, 2008; Granic, Lobel, \& Engels, 2014; Hofferth \& Moon, 2012), and large longitudinal studies suggest that it has no detrimental effects, even at high levels of play, in the population over time (Parkes, Sweeting, Wight, \& Henderson, 2013). Yet a broad group of gaming behaviors which are termed problematic gaming seem to be indicative of behavioral dysregulation (Faulkner, Irving, Adlaf, \& Turner, 2015; Ferguson et al., 2011; Festl et al., 2013) and mirror work outside of gaming suggesting that problematic Internet use, more broadly, is reflective of dysregulation (Widyanto \& McMurran, 2004). Studies that suggest dysregulation underlies such problematic gaming include work linking it to trait-level neuroticism (Peters \& Malesky, 2008), and to other dysregulated behaviors such as cigarette smoking and fighting in adolescents (Desai, Krishnan-Sarin, Cavallo, \& Potenza, 2010). Perhaps because it is dysregulating, problematic gaming may undermine physical, social, and mental health; for example, linking with lower levels of life satisfaction, more anxiety, and more depression in nationwide 
88 surveys (Mentzoni et al., 2011). Evidence here is mixed as well (Gentile et al., 2011), and a meta-

89 analysis of this literature suggests that correlations with mental health are small $(r=.15)$, absent for

90 social health, and effect sizes discrepant across studies for all health outcomes (Ferguson et al., 2011).

91 Indeed, the only large-scale longitudinal study which systematically tests problematic gaming, a German

92 sample of young adults ages 19-39 years, reports inconsistent and weak relations between dysregulated

93 gaming and perceiving oneself as successful, though no lagged effects with life satisfaction were

94 observed (Scharkow et al., 2014).

95 Psychological Need satisfaction

96 Given IGD is a form of problematic gaming that may have its roots in dysregulation, we

97 employ self-determination theory (SDT; Deci \& Ryan, 2000) in an attempt to better understand

98 its etiology and consequences. SDT provides a well-tested empirical framework for

99 understanding how dysregulation occurs and its potential implications for health and functioning.

100 SDT posits that three basic psychological needs foster healthy self-regulation and promote

101 mental and physical health; those for autonomy - or a sense of choice and self-expression,

102 competence - or efficacy to act on the world in desired ways, and relatedness - or feelings of

103 closeness and intimacy with others. Findings consistently show that having psychological needs

104 satisfied is associated with more mental, physical, and psychosocial health (Deci \& Ryan, 2000).

105 For example, those who are need satisfied report fewer symptoms of depression and disordered

106 eating (Bartholomew, Ntoumanis, Ryan, Bosch, \& Thogersen-Ntoumani, 2011; Chen et al.,

107 2015; Luyten \& Blatt, 2013; Nguyen-Rodriguez, Unger, \& Spruijt-Metz, 2009; Soenens, Park,

108 Vansteenkiste, \& Mouratidis, 2012; Verstuyf, Patrick, Vansteenkiste, \& Teixeira, 2012), fewer

109 negative and more positive emotions indicative of mental health (Ryan \& Deci, 2001), better

110 physical health including fewer physical symptoms such as headaches and gastrointestinal 
111 problems (Reinboth, Duda, \& Ntoumanis, 2004; Sheldon, Ryan, \& Reis, 1996; Thompson \&

112 Prottas, 2006), and better psychosocial functioning (H. S. Hodgins, Koestner, \& Duncan, 1996;

113 Moller \& Deci, 2010; Patrick, Knee, Canevello, \& Lonsbary, 2007; Weinstein, Hodgins, \&

114 Ostvik-White, 2011). Psychological support, in the form of basic psychological needs, provide

115 an avenue for understanding Internet gaming and player health. By applying SDT to IGD we can

116 test the role these psychological factors play in fostering dysregulation, and better understand

117 how dysregulation is related to mental, psychosocial, and physical health.

118 Having Psychological Needs Met Reduces Dysregulation. A central question of IGD

119 concerns its antecedents, the conditions under which it might emerge. Based in SDT, we

120 hypothesized that the absence of psychological need satisfaction is a risk factor for such

121 dysregulated Internet gaming. This expectation is informed by previous research suggesting that

122 environments low in need satisfaction have a dysregulating effect during development

123 (Brenning, Soenens, Braet, \& Bosmans, 2012; Roth \& Assor, 2012; Roth, Assor, Niemiec, Ryan,

124 \& Deci, 2009; Roth et al., 2009), contribute to burnout and disengagement (Bartholomew et al.,

125 2011; Van den Broeck, Vansteenkiste, De Witte, \& Lens, 2008), stoke reactive aggression

126 (Przybylski, Deci, Rigby, \& Ryan, 2014; Weinstein, 2009), and foster behavioral addictions

127 (Williams, Hedberg, Cox, \& Deci, 2000).

128 More immediate to the current work, SDT research has been applied to dysregulated

129 technology use in cross-sectional research. The absence of need satisfaction has been linked to

130 excessive use of Facebook and other Internet use (Sheldon, Abad, \& Hinsch, 2011; Williams et

131 al., 2000), whereas its presence has been linked to Internet use that contributes to well-being

132 (Sheldon et al., 2011). Individuals who experience need satisfaction also report lower obsessive

133 passion for videogame play (Przybylski, Weinstein, Ryan, \& Rigby, 2009), as well as play 
134 indicative of more pressure and less enjoyment of the task (Lafrenière, Verner-Filion, \&

135 Vallerand, 2012). In sum, this body of work suggests that need satisfaction reduce the likelihood

136 of behavioral regulation, and as such individuals who experience the satisfaction for these three

137 psychological needs in their day-to-day lives are less likely to engage Internet gaming in a

138 disordered and problematic manner.

139 Dysregulation Reduces Psychological Needs. A second central question concerning

140 IGD has to do with its psychological consequences, the downstream effects that dysregulated

141 gaming might have on need satisfaction and health. Based on a smaller body of work concerning

142 needs and dysregulation, we might expect that IGD would deprive people of need satisfaction

143 over time. In line with this prediction, we would expect a reciprocating relationship between

144 psychological need satisfaction and IGD. Dysregulated players may experience their gaming as

145 disruptive to the fulfillments they might otherwise experience in their daily lives. For example,

146 pathological patterns of engagement might interfere with opportunities to experience a sense of

147 competence by achieving desired goals in the real world, or even in the gaming world if the

148 player feels the play to be more of a compulsion than a gratification. It is also possible that IGD

149 could displace or interfere with other activities such as family meals, social events, and academic

150 or workplace meetups as suggested by relations between problematic gaming and social capital

151 (Scharkow et al., 2014). Although this expectation has not been tested in relation to Internet

152 gaming per se, there is some support for this idea in that individuals who have obsessive passion

153 indicative of dysregulation in the workplace experience less support for the three needs of

154 autonomy, competence, and relatedness (Forest, Mageau, Sarrazin, \& Morin, 2011). Indeed, it

155 may be that those with IGD show poor health because IGD undermines their psychological

156 needs. The literature reviewed above suggests a robust link between psychological need 
157 satisfaction and mental, physical, and psychosocial health. Insofar as IGD undermines needs, it

158 might indirectly impact on these criteria. In line with this idea, workplace need satisfaction in the

159 research discussed above have mediated the link between obsessive passion and mental health

160 (Forest et al., 2011; Przybylski et al., 2009).

\section{Gaming and Everyday Activities}

162 Research has also suggested that problematic gaming may impact players' health and

163 functioning because it reduces the likelihood of engaging social and physical activities (Charlton,

164 2002; Charlton \& Danforth, 2007). Indeed, the displacement hypothesis (Neuman, 1988;

165 Valkenburg \& Peter, 2009) has been applied to understanding screen time more broadly, and

166 suggests that using screens may reduce well-being because it reduces quality time with friends.

167 Evidence from a number of studies suggests the time devoted to Internet-based games could

168 supplant such activities, leading to lower levels of exercise (Sisson, Broyles, Baker, \&

169 Katzmarzyk, 2010) and resulting in increased body mass (Anderson, Economos, \& Must, 2008).

170 At least one study indicates Internet gamers choose less real-world social activity (B. D. Ng \&

171 Wiemer-Hastings, 2005), and additional studies link Internet use to increased levels of social

172 isolation (Kraut et al., 1998). The potential cost to real-life interactions is concerning, because

173 high quality of social interactions are essential for health (e.g., Cohen, 2004; Cohen \&

174 Hoberman, 1983; Seeman, 1996). Data on the effects of gaming time are not uniform, however,

175 as work indicates that some kinds of play may promote physical activity (Lanningham-Foster et

176 al., 2006) and provide important avenues for in-person socialization (Duggan, 2015b; Lenhart,

177 2015). Although these observed effects, for good or ill, on everyday activities are modest

178 (Boone, Gordon-Larsen, Adair, \& Popkin, 2007), they suggest diminished social and physical

179 activity may serve as a bridge that links IGD to poorer health outcomes for players over time, 
180 and may provide a better account of why IGD might result in more costs to health than do

181 subjective experiences of basic psychological needs.

\section{The Present Research}

183

184

185

186

187

188

189

190

191

192

193

194

195

196

197

198

199

200

201

The goal of the present research was to rigorously investigate the etiology and personal outcomes of Internet Gaming Disorder and to expand what is empirically known about the health effects of this potential psychiatric disorder. To this end we conducted a prospective longitudinal study with a large and representative adult cohort informed by DSM-5 guidance (Hasin et al., 2013; Kardefelt-Winther, 2014b) and motivational theory (Deci \& Ryan, 2000; Ryan \& Deci, 2000), using an approach grounded in open science methodology (Morey et al., 2016).

In this study we evaluated confirmatory hypotheses (i.e., a priori and pre-registered) and conducted exploratory analyses (e.g., data and theory driven, but not pre-registered) concerned with the antecedents and consequences of Internet Gaming Disorder (Cumming, 2012;

Wagenmakers, Wetzels, Borsboom, Maas, \& Kievit, 2012). By making this distinction, summarized in Table 1, we were able to draw robust conclusions about IGD by rejecting or upholding our a priori hypotheses, and to explore theoretically important questions after the data were known (Ioannidis, 2012). Our first set of confirmatory predictions concerned the temporal stability of IGD, need satisfaction, and health. We hypothesized that the observation of each factor at the start of the study would be linked to the same factor at the end of the study (Hypotheses 1-3); Testing these direct effects also served as a control for the cross-lagged paths. Building on motivational work indicating that the absence of need satisfaction leads to dysregulated behaviour, our second set of confirmatory hypotheses concerned the interrelations between psychological needs, health, and IGD. We anticipated that need support would predict fewer IGD symptoms six months later (Hypothesis 4), and we expected reciprocal effects with 
203 need satisfaction such that IGD symptoms at the start of the study would also undermine need

204 satisfaction six months later (Hypothesis 5). Informed by the motivational literature linking

205 psychological needs to mental, social, and physical health we anticipated that need satisfaction at

206 the start of the study would link to health six months later (Hypothesis 6). Moreover, based on

207 the extant literature on dysregulated gaming we expected that IGD symptoms at the start of the

208 study would predict poorer health six months later (Hypothesis 7).

To supplement the confirmatory model and data, we also conducted several exploratory

analyses based on motivational theory. Providing that we could find support for the hypothesized

211 cross-lagged model, and that it can hold over a longer time period (i.e. equilibrium assumption),

212 the model also tests if psychological need satisfaction would serve as a mediator between IGD

213 and health outcome (Little, Preacher, Selig, \& Card, 2007). We examined this possible

214 mechanism by directly reporting the mediation effect computed in the confirmatory model

215 (Figure 1), but did not pre-register this hypothesis (Exploratory Analysis 1). Furthermore,

216 consistent with SDT, we investigated the extent to which the individual basic psychological

217 needs for competence (Exploratory Analysis 2), relatedness (Exploratory Analysis 3), and

218 autonomy (Exploratory Analysis 4) need satisfaction serve as mediators for the linkage between

219 IGD and health. It may be that only one need, for example, lower experiences of competence,

220 carries effects identified with IGD symptoms. Finally, we examined the possibility that IGD

221 symptoms, as a form of problematic gaming, may displace real-life social and physical activity

222 (Lanningham-Foster et al., 2006; Neuman, 1988; Sisson, Broyles, Baker, \& Katzmarzyk, 2010),

223 and by doing so undermine health (Cohen, 2004; House, Landis, \& Umberson, 1988). We tested

224 this possibility in two alternative models that add these factors to the confirmatory model (see

225 Figure 2). On this basis we expected that these two activities might link directly to health 
226 (Exploratory Analyses $5 \&$ 6) and mediate the relations between IGD and health (Exploratory

227 Analyses $7 \& 8$ ).

228

\section{Materials \& Methods}

229 Participants

230 Data were collected at two time points with participants recruited through YouGov's 1.8

231 million person Internet-based American panel. Following an approach used in previous

232 behavioral health research (e.g., Cranwell, Opazo-Breton, \& Britton, 2016; Reeves, Halsey,

233 McMeel, \& Huber, 2013) panelists were selected at random from the panel using quotas

234 informed by 2010 U.S. Census data and pre-captured information about panelists' age, gender,

235 ethnicity, and geographic region. Fieldwork was conducted between October 2015 and March

236 2016. From this, a nationally representative sample of 5,777 adults aged 18 years and older from

237 the United States completed the initial assessment as part of an ongoing project studying Internet

238 Gaming Disorder (see: (Przybylski et al., 2016a) and a total of 4,594 completed the follow-up

239 measures six months later. Consistent with our earlier IGD research (Przybylski et al., 2016a),

240 we focused on participants who recently played Internet games at the time of assessments, a total

241 of 2,316 individual ( 885 males and 1431 females) played Internet games at both time points.

242 This subsample ranged in age from 19 to 91 years $(M=49.21, S D=1.32)$, of which 1,689

243 (72.9\%) identified as White, $246(10.6 \%)$ as Black, $184(7.9 \%)$ as Hispanic, $69(3.0 \%)$ as Asian,

$24421(0.9 \%)$ as Native American, $3(0.2 \%)$ as Middle Eastern, and $101(4.4 \%)$ as mixed race or

245 another identification. In terms of educational attainment, 75 (3.2\%) had not completed

246 secondary school, 659 (28.5\%) completed secondary school, 598 (25.8\%) completed some

247 college, 257 (11.1\%) completed a two-year degree, 504 (21.8\%) completed a four-year degree,

248 and 223 (9.6\%) completed a post graduate degree. Estimates of total annual household income 
249 were provided by 2,316 participants, these ranged from less than $\$ 10,000(6.3 \%)$ more than

$250 \$ 500,000$ a year $(0.2 \%)$ with most $(77 \%)$ reporting between $\$ 10,000$ and $\$ 150,000$. The

251 distributions of participants were broadly similar to those of videogame players, who tend to be

252 equally divided among men and women and whose average age, including players under the age

253 of 18 years, is 35 years (Pew Research Centre, 2015), yet females were somewhat

254 overrepresented at $60.8 \%$ in the final sample.

255 Ethical Review

256 Ethical review for data collection and analysis was conducted by the research ethics

257 committee at the University of Oxford (C1A15006). All participants polled for the present

258 research were above 18 years of age and members of the YouGov American panel. Panel

259 participants completed a double opt-in process that involved both agreeing to the YouGov Terms

260 and Conditions (YouGov, 2017a) meaning they were willing to be contacted as part of

261 participating a member of the Internet-based YouGov Omnibus panel generally, and they agreed

262 to participate in the present study. In line with the YouGov Privacy Policy (YouGov, 2017b), the

263 investigators did not have access to any uniquely identifying participant information. Participants

264 could contact investigators using by way of email contact at YouGov. No inquiries linked to the

265 present studies were received.

266 Measures

267 Internet gaming disorder. Participants completed a nine-item criteria checklist drafted

268 in consultation with clinical and research psychologists studying video games and behavioral

269 addictions and applied in two previous investigations of IGD (Przybylski, 2016; Przybylski et al.,

270 2016a), and included items such as "I felt moody or anxious when unable to play", "I felt that I

271 should play less but couldn't", and "risked friends or opportunities due to games". More than half 
272 of participants reported no criteria at the first time point $(70.0 \%)$ or at follow-up (73.2\%). The

273 proportion of participants decreased as the number of criteria endorsed increased for both the

274 first and follow-up period. Overall, participants endorsed a small number of criteria $(M=0.56$,

$275 S D=1.13$ at $\mathrm{T} 1 ; M=0.47, S D=0.97$ at $\mathrm{T} 2$ ). APA recommendations for clinical levels of IGD

276 include endorsing five or more of the nine criteria (Hasin et al., 2013; Petry et al., 2014) paired

277 with endorsement of personal distress due to Internet gaming use (American Psychiatric

278 Association, 2013). The proportion of participants who endorsed five or more criteria was $1.49 \%$

$279(95 \% \mathrm{CI}=[1.11 \%, 2.00 \%])$ at the first time point and $0.99 \%(95 \% \mathrm{CI}=[0.65 \%, 1.51 \%])$ at

280 follow-up, and only a very small proportion of participants endorsed the statement that they

281 "suffered significant distress due to gaming" in the past six months, the criteria for addiction as

282 identified in earlier research (Przybylski et al., 2016a): 0.38\% (95\% CI $=[0.21 \%, 0.68 \%])$ at the

283 first time point and $0.30 \%(95 \% \mathrm{CI}=[0.13 \%, 0.65 \%])$ at the end of the study. Interestingly,

284 only three participants reported more than four IGD criteria at both observed time points and

285 none of the participants who met a diagnostic threshold including distress at the start did so at the 286 end of the study.

287 Internet gaming. Participants were asked to reflect on the past six months of their lives 288 and rate how frequently they engaged in online gaming: "Played video/computer games online 289 (e.g. Candy Crush, Minecraft, or Farmville)," using a 5-point response scale that ranged from 1 290 "Never" to 5 "Every day or almost every day". Of those who said they engaged with Internet 291 games, a total of $44.3 \%(95 \% \mathrm{CI}=[42.6 \%, 46.1 \%])$ said they played every day , $25.3 \%(95 \% \mathrm{CI}$ $292=[23.8 \%, 26.8 \%])$ played once or twice a week, $11.4 \%(95 \% \mathrm{CI}=[10.4 \%, 12.6 \%])$ once or 293 twice a month, and $18.9 \%(95 \% \mathrm{CI}=[17.6 \%, 20.4 \%])$ less often at the start of the study. At the 294 end of the study $46.5 \%(95 \% \mathrm{CI}=[44.4 \%, 48.5 \%])$ said they played everyday, $24.5 \%(95 \% \mathrm{CI}$ 
$295=[22.8 \%, 26.3 \%])$ played once or twice a week, $11.1 \%(95 \% \mathrm{CI}=[9.9 \%, 12.5 \%])$ once or

296 twice a month, and $18.0 \%(95 \% \mathrm{CI}=[16.4 \%, 19.6 \%])$ reported playing less often.

297 Health. A three-item scale was used to tap into participant health (Ahmad, Jhajj, Stewart, 298 Burghardt, \& Bierman, 2014). Participants were asked to reflect on the past six months of their

299 lives and rate their social, mental, and physical health using a 5-point response scale that ranged

300 from 1 "Poor" to 5 "Excellent". Individual scores were averaged for Time $1(\alpha=.78, M=3.26$,

$301 S D=0.94)$ and Time $2(\alpha=.78, M=3.26, S D=0.93)$.

302 Psychological need satisfaction. A three-item motivation scale was used to tap into

303 participant psychological need satisfaction, taken from the widely used Basic Psychological

304 Needs Scale (BPNS; La Guardia, Ryan, Couchman, \& Deci, 2000). Participants were asked to

305 reflect on the past six months and rate their experience of satisfaction for the needs for

306 autonomy, competence, and relatedness using a 5-point response scale that ranged from 1 "Not

307 at all true" to 5 "Very true". Individual scores were averaged for Time $1(\alpha=.81, M=3.89, S D$

$308=0.96)$ and Time $2(\alpha=.82, M=3.90, S D=0.98)$.

309 Physical and social activity. Two single-item scales were used to measure everyday

310 behavior (Laganà, Bratly, \& Boutakidis, 2011; Milton, Bull, \& Bauman, 2011). Participants were

311 asked to reflect on the past six months of their lives and rate how frequently they engaged in

312 social activity: "Spent quality time with friends or family (e.g., playing games, picnics, or

313 reading)" and physical activity: "Engaged in physical exercise indoors or outdoors (e.g., gym,

314 aerobics, or sports)", using a 5-point response scale that ranged from 1 "Never" to 5 "Every day

315 or almost every day".

316 Convergent validation. To evaluate the extent to which these abbreviated assessments

317 mapped onto well-established assessments of health and motivational processes, an independent 
318 sample of 507 American adults (228 male, 273 female, 6 transgender, gender non-conforming, or

319 other) were recruited using the Amazon Mechanical Turk platform. Ethical review was

320 conducted by the research ethics committee at the University of Oxford and participants were

321 compensated $\$ 1.20$ to complete this brief survey which assessed our primary study measures as

322 well as need satisfaction using the Basic Need Satisfaction and Frustration Scale (Chen et al.,

323 2015), mental health using the Warwick-Edinburgh mental well-being scale (Clarke et al., 2011),

324 social and physical health using the MOS-36 (Sherbourne \& Stewart, 1991; Ware \& Sherbourne,

325 1992), and health-related anxiety using the HAI-18 (Salkovskis, Rimes, Warwick, \& Clark,

326 2002). Linear models regressing longer measure scores onto our primary study measures

327 indicated our brief measures of basic psychological need satisfaction $(\beta=.78)$, mental health $(\beta$

$328=.68)$, social health $(\beta=.50)$, and physical health $(\beta=.74)$ were highly correlated with the

329 longer well-validated assessments. More importantly, results from a model regressing physical

330 health scores (Ware \& Sherbourne, 1992) simultaneously onto our brief physical health measure

$331(\beta=.60)$ and a measure of health anxiety $(\beta=-.31$; Salkovskis, Rimes, Warwick, \& Clark, 2002)

332 indicated our brief assessment successfully tapped variance linked with perceptions of health.

Results

334 Data and Analytic Strategy

Study data, code, materials (Przybylski, Weinstein, \& Murayama, 2017), and registered

analysis plan (Przybylski, Weinstein, \& Murayama, 2016b), are available for download using the

337 Open Science Framework. Following this registered analysis plan, we modelled temporal

338 ordering using a Granger's causality approach, a cross-lagged model (Finkel, 1995; Menard,

339 2002; see also Marsh et al., 2016 for an application) where observations at follow-up were

340 jointly predicted by measurements at the start of the study (see Figure 1). Exploratory analyses 
341 concerning mediation and models examining physical and social activity (see Figure 2) are also

342 conducted. Figure 3 presents the empirical findings in line with the preregistered analysis plan.

343 There was one noteworthy deviation from the registered analysis plan which concerned

344 examining IGD diagnoses in line with DSM-5 guidance (Hasin et al., 2013) and previous

345 research on IGD (Przybylski et al., 2016a). Contrary to expectations, none of the participants

346 who met the diagnostic threshold, that is, endorsed five or more items and experienced distress

347 as a result of their game use at the start of the study also did so at follow-up. This unexpected

348 result suggests formal diagnoses might not be stable over time. Our analyses therefore only

349 present the alternative, also preregistered, approach for operationalizing IGD; that is, summing

350 the number of endorsed criteria.

351 All the analyses were conducted with structural equation modelling using Lavaan

352 (Rosseel, 2012). In the current sample, participants who dropped out and those who stayed have

353 different average IGD scores, $M=0.71, S D=1.13$ and $M=0.50, S D=1.04$, respectively, $t$

$354(3,144)=4.43, p<.01$. To account for this attrition bias, we used full-information maximum-

355 likelihood method to estimate parameters. This method allow us to account for attribution bias in

356 estimating parameters by including the variables that are correlated with $\mathrm{T} 2$ attrition in the

357 analysis (e.g., T1 IGD). (e.g., T1 IGD) (Jeličić, Phelps, \& Lerner, 2009). All the models we

358 analyzed were saturated (i.e. degree of freedom was zero). To account for this attrition bias, the

359 full information maximum likelihood estimator was implemented in the lavaan package.

360 Analyses were also conducted controlling for participant age and gender, and the results were

361 consistent with those reported below. Linear coefficients, beta values, reported below reflect

362 standardized units of change in the outcome variable as a function of one unit of change in the

363 predictor variable. 


\section{Confirmatory Findings}

365 In line with our registered analysis plan, we examined hypotheses concerned with the

366 causes of Internet Gaming Disorder, psychological need satisfaction, and health using a cross-

367 lagged model.

368 Internet Gaming Disorder. We tested our expectation that IGD at follow-up would be

369 predicted by standing at the start of the study in two ways. Results from phi coefficient analyses

370 indicated that IGD appeared stable on a criterion level, coefficients ranged from a low of $r=$

3710.18 , for experiences of withdrawal when Internet games were not played, to $r=0.31$, for using

372 Internet games as an escape from negative mood. Results from cross-lagged analyses (see Figure

373 1) confirmed the hypotheses that IGD at the start of the study $(\beta=.42, p<.001$; Hypothesis 1$)$

374 and basic need satisfaction $(\beta=-.08, p<.001$; Hypothesis 4$)$ were causally related to IGD at

375 follow-up. The model also indicated health at the start of the study was not associated with later

376 standing on IGD $(\beta=-.01, p=.74)$.

377 Psychological need satisfaction. Results from the planned cross-lagged analysis (Figure

378 1) supported the hypotheses that need satisfaction at the start of the study would be positively

379 predictive $(\beta=.56, p<.001$; Hypothesis 2$)$, whereas IGD would negatively influence $(\beta=-.06$,

$380 p<.001$; Hypothesis 5) need satisfaction. Though the effects observed were small they were

381 consistent with our hypothesis suggesting that IGD could be disruptive to this form of

382 psychological functioning. Though it was not hypothesized, the model also indicated health at

383 the start of the study was associated with later standing on need satisfaction $(\beta=.17, p<.001)$.

Health. Findings from the causal model confirmed our hypothesis regarding the temporal

385 stability of health $(\beta=.72, p<.001$; Hypothesis 3$)$ and the positive contribution of basic

386 psychological need satisfaction to subsequent health $(\beta=.07, p<.001$; Hypothesis 6$)$. Contrary 
387 to what was hypothesized (Hypothesis 7$)$, IGD at the start of the study $(\beta=.01, p=.66)$ did not

388 predict lower levels of health at follow-up. This unexpected result provided evidence that there is

389 no direct effect of dysregulated Internet gaming on adult health over time.

390 Sensitivity analysis. Using our IGD measure, participants reported few IGD criteria ( $M$

$391=0.47$ at $\mathrm{T} 2$, out of 9 criteria). Although we employed a robust estimation method to account for

392 non-normality, responses to this scale may not be best described as a normal distribution. To

393 address the issue, we conducted negative binomial regression analysis predicting T2 IGD from

394 T1 IGD, T1 need satisfaction, and T1 health (all the independent variables were standardized) to

395 directly take into account the discrete count nature of the data with low occurrence rate (the part

396 of our model that is susceptible to this issue is depicted in Figure 1). The results were entirely

397 consistent with the SEM results $\left(\mathrm{B}_{\text {TIIGD }}=.65, p<.01 ; \mathrm{B}_{\text {TIHealth }}=-0.06, p=.20 ; \mathrm{B}_{\text {TINeeds }}=-0.20\right.$,

$398 p<.01)$, indicating findings were robust.

399 Exploratory Analyses

$400 \quad$ Mediating influence of basic psychological needs. The cross-lagged modelling

401 approach used to test the confirmatory hypotheses also provided evidence regarding the indirect

402 effects of IGD and health (Little, Preacher, Selig, \& Card, 2007; see for an application, Bishop,

403 Martin, Poon, \& Johnson, 2011). If a model provides evidence for the effects of IGD on basic

404 psychological needs, and for the effects of basic psychological needs on health, this supports an

405 equilibrium assumption (i.e., that the same relationship holds beyond the two time points we

406 assessed). As such, we can infer that IGD has indirect effects on health by its impact on basic

407 psychological needs. Results provided clear evidence that IGD was indirectly linked to health

408 through the support for basic psychological needs (see Table 2; Exploratory Analyses 1-4). All

409 three further cross-lagged mediation models evaluating competence, relatedness, and autonomy 
410 separately exhibited significant mediation effects (Table 2). Taken together, these results suggest

411 each of the three needs has a mediating effect.

412 Social and physical activity. IGD may displace real-life social and physical activity, and

413 by doing undermine health directly (Sisson et al., 2010) or indirectly by relating to need

414 satisfaction (Mellor, Stokes, Firth, Hayashi, \& Cummins, 2008; J. Y. Y. Ng et al., 2012; Wilson,

415 Rodgers, Blanchard, \& Gessell, 2003). Given this, the mediating effects of psychological need

416 satisfaction might be apparent because need satisfaction correlates with social activity, and these

417 activities provide a better account for the harmful effects of IGD on health than do needs. To test

418 this alternative explanation, we evaluated two additional cross-lagged models that included either

419 social or physical activity (see Figure 2; Exploratory analyses 5 \& 6). Results showed social $(\beta=$

$4200.42, p<.01)$ and physical $(\beta=.62, p<.01)$ activity were consistent over time and supported our

421 expectations that physical activity at Time 1 would be associated with later health $(\beta=0.07, p<$

$422.001)$, although social activity at Time $1 \mathrm{did}$ not relate to health at Time $2(\beta=0.02, p=.21)$.

423 Contrary to our expectations (Exploratory analyses $7 \& 8$ ), those who exhibited more IGD

424 symptoms at Time 1 did not report different levels of social $(\beta=0.01, p=.68)$, or physical $(\beta=$

$4250.02, p=.12$ ) activity at Time 2 . Thus, we did not find support for indirect effects through these

426 activities. Moreover, links identified between IGD at Time 1 and needs at Time 2, and between

427 needs at Time 1 and health at Time 2 (the two links suggesting the presence of an indirect

428 effect), were significant controlling for activity levels (for the link between IGD and need

429 satisfaction, controlling for physical activity; $\beta=-0.06, p<.001$, controlling for social activity; $\beta$

$430=-0.06, p<.001$; for the link between need satisfaction and health, controlling for physical

431 activity; $\beta=0.09, \mathrm{p}<.001$; controlling for social activity; $\beta=0.07, \mathrm{p}<.001$ ). This constellation

432 of results suggests that the effects of IGD on social or physical activities do not provide a 
433 compelling alternative account of why IGD undermines health over time to that offered by need

434 satisfaction.

435

436

437

438

440

441

442

443

444

445

446

447

448

449

450

451

452

453

454

455

\section{Discussion}

Internet-based games are among the most popular forms of human recreation and empirical research is still needed to understand possible psychopathology related to their use. The present research rigorously investigated the etiology and outcomes of Internet Gaming Disorder and the findings derived from this prospective study inform our understanding of how this phenomenon is linked to dysregulation and health. Guided by an open science approach, results confirmed a number of our preregistered hypotheses concerning dysregulated online play. In line with predictions we found that the IGD criteria proposed in the DSM-5 (American Psychiatric Association, 2013) were, on an individual and continuous basis, moderately stable over a six month period. Contrary to what we expected, however, none of the participants meeting diagnostic thresholds at the start did so at the end of the study, and only three participants reported more than four IGD criteria at the start and six months later. These findings, that very few, if any, individuals who meet the proposed diagnostic thresholds over time mirror those derived from other large-scale representative studies of problematic gaming research (Festl et al., 2013; Scharkow et al., 2014). These unexpected results do not support a theoretical framing of Internet Gaming Disorder as a chronic psychiatric condition akin to substance abuse disorder as some have argued (e.g., Hasin et al., 2013; Petry et al., 2014); Rather, the constellation of results we uncovered provide evidence that dysregulated gaming is a nuanced phenomenon that requires careful conceptualisation, and one which can be fruitfully studied from a motivational perspective (Deci \& Ryan, 2000; Griffiths et al., 2016; Kardefelt-Winther, 2014b). These results may also speak to the nature of the proposed disorder. For example, they 
456 mirror some research on problematic gambling, another kind of behavioural dysregulation,

457 which shows such difficulties are more episodic than continuous (Slutske, Jackson, \& Sher, 458 2003), though it is unclear whether these IGD episodes are chronic across a span of multiple

459 years, similar to models of addiction where the individual is never truly free of the illness but 460 only experiences intermittent expressions of it (Saitz, Larson, LaBelle, Richardson, \& Samet, 461 2008), possibly as an expression of maladaptive coping (Kardefelt-Winther, 2014a). With this in

462 mind, further research investigating the nature of IGD as chronic or episodic would be useful.

463 Generally, IGD has been measured in terms of its more or less frequent occurrence across a

464 period of 12 months (Pontes, Király, Demetrovics, \& Griffiths, 2014), but a lack of stability in

465 clinical thresholds being met across a six-month period suggest that these symptoms would need

466 to be frequently reoccurring over a 12-month period for them to be captured by these longer-term 467 assessments.

468 Also contrary to our expectations, we did not find that IGD had an observable direct 469 effect on health over time. Although this finding is inconsistent with some results derived from 470 small-scale convenience samples, it is in line with the only other representative longitudinal 471 work which suggests mixed or non-significant lagged effects linking problematic gaming with

472 life satisfaction and perceived success of gamers (Scharkow et al., 2014). This negative finding 473 is especially noteworthy because it indicates that IGD may not, on its own, be robustly 474 associated with important clinical outcomes. As such, it may be premature to invest in 475 management of IGD using the same kinds of approaches taken in response to substance-based 476 addiction disorders, for example with TMS (Meng, Liu, Yu, \& Ma, 2014; Shen et al., 2016;

477 Terraneo et al., 2016). Further, this pattern of findings suggests that more high-quality evidence 
478 regarding clinical and behavioral effects is needed before concluding this is a legitimate

479 candidate for inclusion in future revisions of the DSM-5.

480 Despite the absence of a direct link with health, additional research findings indicated

481 there is reason for concern when individuals exhibit IGD symptoms. Informed by the human

482 motivation and self-regulation literature on psychological needs (Ryan \& Deci, 2000), we

483 predicted and found that those who were not psychologically need satisfied were more likely to

484 evidence symptoms of IGD at a later time. Though the observed relations were not large in

485 magnitude, they suggested that IGD symptoms can emerge from dysregulating environments or

486 dysregulated psychological states brought on by the absence of psychological need satisfaction,

487 in line with other symptoms indicative of psychopathology, such as depression and anxiety (Deci

488 et al., 2001; Talley, Molix, Schlegel, \& Bettencourt, 2010; Wei, Shaffer, Young, \& Zakalik,

489 2005), disordered eating (Bartholomew et al., 2011), and borderline personality disorder (Ryan,

490 2005).

491 In line with this idea and the research reviewed above, it may also be that endorsing IGD

492 criteria may be characteristic of a broader and more pervasive problem with self-regulation.

493 Indeed, work with individuals who exhibit gambling disorder, the only non-substance related

494 addiction which is recognized in the DSM-5, shows a lifetime prevalence rate of $61 \%$ for mood

495 disorders, $75 \%$ for alcohol use, and $48 \%$ for drug use, rates higher than in the general population

496 and which reflect a history of dysregulation (D. C. Hodgins, Peden, \& Cassidy, 2005). Given we

497 did not test comorbidity with other clinical disorders, or lifetime prevalence of other clinical

498 disorders in those who exhibit IGD symptoms, future research doing so would greatly enhance

499 our understanding of the nature of the disorder and its treatment. 
501 that those who exhibited symptoms of IGD were less likely to be need satisfied later. This

502 observed pattern of joint causality between needs and IGD suggests that the dynamics underlying

503 unhealthy behaviors mirror those observed in other life contexts (Forest et al., 2011). In addition,

504 the confirmation of this hypothesis indicates that dysregulated gaming may be detrimental to

505 experiencing psychological need satisfaction through other avenues and may crowd out more

506 psychologically edifying pursuits (Chen et al., 2015); For example, IGD symptoms may directly

507 interfere with pursuing other meaningful life goals that satisfy needs (Niemiec, Ryan, \& Deci,

508 2009). Alternatively or in addition to this, the experience of compulsion and obsession may

509 directly leave individuals feeling that they have less choice, more isolated and lonely, and

510 ineffective (Lalande et al., 2015).

511 Our data were collected from two time points but with a certain reasonable assumption,

512 we can infer potential mediational process from the cross-lagged model that we tested (Liettle et

513 al., 2007). Indeed, findings from the prespecified model suggested that need satisfaction

514 mediated the effects of IGD symptoms on health; that is, the results indicated that IGD decreases

515 health through lowering need satisfaction. In other work, such need satisfaction have been shown

516 to relate to the health criteria we have tested in this study; that is, better mental health (Ryan \&

517 Deci, 2001), better physical health (Reinboth et al., 2004; Sheldon et al., 1996; Thompson \&

518 Prottas, 2006), and better psychosocial functioning (H. S. Hodgins et al., 1996; Moller \& Deci,

519 2010; Patrick et al., 2007; Weinstein et al., 2011). The current work extends this literature by

520 suggesting that such costs to health are accrued when dysregulating or pathological behaviors

521 undermine need satisfaction. Further, it informs the IGD and the behavioral addiction literatures 
522 by highlighting that IGD symptoms lead to lower health partly because they undermine need 523 satisfaction.

$524 \quad$ Interestingly, in exploratory analyses we found that all three psychological needs served

525 to link IGD to health. Although the three needs are often tested in sum (e.g., La Guardia et al., 526 2000), additional information can be gained by evaluating their separate impacts on wellness

527 (Sheldon et al., 1996; Weinstein \& Ryan, 2010), and they have been shown to differentially 528 affect psychological outcomes in certain contexts (e.g., Legate, DeHaan, Weinstein, \& Ryan, 529 2013). Evidence that each has a direct effect excludes the possibility that, as an example, IGD 530 induces a feeling of loneliness (absence of relatedness need) that is so robust it carries results 531 using the full measure of need satisfaction.

532 Our final two models assessed whether social and physical activity accounted for the link 533 between IGD symptoms and health, an especially important test given these activities may have

534 been responsible for the indirect effects through psychological needs observed in earlier

535 analyses. The data did not support this conclusion, and instead showed none of the expected 536 relations between IGD symptoms and later costs to social and exercise behaviours. These

537 findings are in line with a mixed literature in this area (Boone et al., 2007), including descriptive 538 research which identifies that $83 \%$ of adolescents feel more connected to their friends through

539 their technology use, and suggesting that $68 \%$ say they have received social support using 540 technology in tough or challenging times (Lenhart et al., 2015). It is also consistent with findings 541 that gaming can at times promote physical activity (Lanningham-Foster et al., 2006), and work

542 which fails to identify a consistent relation between gaming and physical activity (Kremer et al., 543 2014; Mentzoni et al., 2011). In this study, we found that dysregulated gaming did not result in 544 actual social isolation or physical inactivity, and that the subjective experience of psychological 
545 need satisfaction continues to link IGD to health even controlling for these activities. Yet it

546 might be that IGD symptoms interfere with other meaningful activities not tested in this research

547 that might undermine need satisfaction and provide a more direct account of why IGD

548 undermines health. For example, as discussed above IGD may interfere with the pursuit of

549 meaningful goals, or with academic or work responsibilities. In future work, researchers may test

550 the possibility that engagement in other daily activities might provide a better account than

551 physical or social activity.

552 It is important to note that much of the existing literature on IGD has relied on

553 convenience samples of young adult volunteers drawn from online gaming forums (e.g., Pontes,

554 Király, Demetrovics, \& Griffiths, 2014). This approach that differs markedly from studying the

555 phenomenon in a representative sample of adults of all ages. Though the former approach

556 presents serious challenges for generalisability and the two populations may be different in terms

557 of how they cope with daily experiences (e.g., Compas, Connor-Smith, Saltzman, Thomsen, \&

558 Wadsworth, 2001; Garnefski, Legerstee, Kraaij, Van Den Kommer, \& Teerds, 2002), we expect

559 that the mechanisms which we have examined here - namely basic psychological needs to have

560 similar explanatory power in both. This is in no small part because nearly 40 years of SDT

561 research has studied the impact of need satisfaction in diverse populations and across

562 developmental stages in non-digital contexts. Indeed, psychological needs are shown to be

563 comparably important in terms of both self-regulation and coping for children, adolescents, and

564 adults (see review in Ryan \& Deci, 2017).

\section{Limitations}

566 The present research has a number of limitations which future research can address to

567 improve our empirical understanding of self-regulation and IGD. First, the study presented relied 
568 on self-reports provided at two time points. The use of respondents for explanatory and criterion

569 data collected misses the opportunity for considering converging and diverging information from

570 the broader social context (Campbell \& Fiske, 1959; Cronbach \& Meehl, 1955), and the

571 inferences we draw in these structural models rests on an assumption of equilibrium. Given the

572 reliance on a brief self-report measure, we may not have fully examined the construct of

573 psychological distress given the clinical framework conceptualizes this as "clinically significant

574 impairment or distress." In future research both aspects of this criterion - that is, significant

575 impairment and distress - must be evaluated carefully and separately. For example, it might be

576 that an individual with IGD does not experience distress, but his or her game playing disrupts

577 academic or professional performance in a meaningful way. Previous research has shown that

578 such questions may vary in suitability as self-reports - that is in some cases but not all

579 individuals are able to make accurate self-assessments (Clancy \& Gove, 1974; Murphy \&

580 Schachar, 2000; Weiss et al., 1998). Future studies could therefore collect reports of health and

581 behaviour from friends, family, or caregivers as well as direct behavioural observations of

582 gaming patterns using gaming logs and collected data at a greater number of time intervals so

583 that an equilibrium assumption can be relaxed in modeling to infer mediation processes.

584 Second, the present data cannot speak to the motivation dynamics of the specific games

585 participants played (e.g. Przybylski, Rigby, \& Ryan, 2010). Given that the current data suggest

586 motivational factors such the absence of basic need satisfaction is part of problematic play,

587 future studies of Internet Gaming Disorder should examine motivational factors outside of and

588 within games. Third, the study focused on a sample of American adults. Particular concerns have

589 been expressed about the potential effects of Internet gaming on cohorts we did not study,

590 including young people and those living in Eastern societies (American Psychiatric Association, 
591 2013). Our sample of individuals from the general population may not have been sensitive to the

592 dynamics underlying extreme and rare cases of problematic gaming, which may show a different

593 pattern of play (for example, these players may exhibit a more continuous nature to their

594 disordered play). Future studies could examine the health and dysregulated play correlates of

595 IGD in samples of younger participants such as school aged children and in other cultural

596 milieus such as Eastern societies where the social nature of online games differ. Fourth, the study

597 design involved a six-month long latency between measures, which allowed for testing lasting

598 effects but may not have been particularly sensitive to immediate causal effects on or by IGD.

599 This is especially problematic if the nature of the disorder involves short-term increases and

600 declines in symptoms over a period of days. Future studies testing the model across varied

601 latencies will be important, for example using daily diary methodology that is more sensitive to 602 experiences as they occur (Wheeler \& Reis, 1991).

603 In addition, despite recruiting a large sample, the number of participants endorsing 604 multiple IGD criteria was quite low. This low prevalence limits the complexity of models that 605 can be applied to the data at this scale, and is a generally unacknowledged problem in the field 606 (for an exception see: Festl et al., 2013). Given that resource intensive large-scale data are 607 needed to accurately study the phenomenon, we strongly suggest that researchers pool their 608 efforts and openly share their data, code, and materials. This will limit duplicate and divergent 609 efforts arising from less systematic approaches. Finally, the study only examined links between 610 IGD and motivational and health outcomes. If indeed IGD is a pervasive or special case of 611 behavioural dysregulation it should have a material and pervasive influence on self-control in 612 other domains (Chen et al., 2015; Deci \& Ryan, 2000; Steel \& Blaszczynski, 1998). Therefore, 
613 future studies could also examine the relations between IGD and psychosocial functioning in

614 school, work, and other recreational contexts.

615

616

617

618

619

620

621

622

623

624

625

626

627

628

629

630

631

632

633

634

635

\section{Conclusions}

The possibility that future revisions of the Diagnostic and Statistical Manual of Mental

Disorders may codify Internet Gaming Disorder as a psychiatric condition meriting clinical attention and resources is controversial (Aarseth et al., 2016). Given the high professional and reputational stakes, studies purporting to investigate the phenomenon must complement robust theory with transparent scientific practices. The present work represents our concerted effort to this end. We used self-determination theory as a lens to study the need and health consequences of IGD and utilized a robust open-science empirical approach. Our use of SDT, open materials, open data, and clearly distinguished confirmatory hypotheses (i.e., pre-registered) and exploratory analyses informs the existing literature. By building on this foundation, our findings speak meaningfully to the etiology and health impacts of IGD. They suggest that IGD has dynamics of dysregulations brought on by the absence of psychological need satisfaction in one's environment, and that it has implications for health, but only by undermining need satisfaction further.

This work also provides some data to guide future work in this area. For example, we found evidence that individual IGD symptoms may remain stable over a brief period of time, yet individual diagnoses appear not to be. Support for the basic psychological needs for competence, autonomy, and relatedness lead to declines in IGD over time, though we did not observe direct effects of IGD on health over time. Tentative evidence consistent with motivational theory suggested IGD may have an indirect effect on health insofar as it undermines need support, yet further research is needed to determine the conditions under which such links endure. Only when 
636 such steps are taken will we know if the attention that researchers and clinicians give to the 637 potential darker aspects of this immensely popular Internet-based activity is fully justified. 638

639 
640

641 Aarseth, E., Bean, A. M., Boonen, H., Colder Carras, M., Coulson, M., Das, D., ... Van Rooij,

\section{References}

643

644

645

646

647

648

649

650

651

652

653

654

655

656

657

658

659

660

661

662 A. J. (2016). Scholars' open debate paper on the World Health Organization ICD-11 Gaming Disorder proposal. Journal of Behavioral Addictions, 1-4. https://doi.org/10.1556/2006.5.2016.088

Ahmad, F., Jhajj, A. K., Stewart, D. E., Burghardt, M., \& Bierman, A. S. (2014). Single item measures of self-rated mental health: a scoping review. BMC Health Services Research, 14, 398. https://doi.org/10.1186/1472-6963-14-398

American Psychiatric Association. (2013). Diagnostic and statistical manual of mental disorders (DSM-5). American Psychiatric Pub.

Anderson, S. E., Economos, C. D., \& Must, A. (2008). Active play and screen time in US children aged 4 to 11 years in relation to sociodemographic and weight status characteristics: a nationally representative cross-sectional analysis. BMC Public Health, 8(1), 366. https://doi.org/10.1186/1471-2458-8-366

Baranowski, T., Buday, R., Thompson, D. I., \& Baranowski, J. (2008). Playing for Real. American Journal of Preventive Medicine, 34(1), 74-82.e10. https://doi.org/10.1016/j.amepre.2007.09.027

Bartholomew, K. J., Ntoumanis, N., Ryan, R. M., Bosch, J. A., \& Thogersen-Ntoumani, C. (2011). Self-Determination Theory and Diminished Functioning: The Role of Interpersonal Control and Psychological Need Thwarting. Personality and Social Psychology Bulletin, 37(11), 1459-1473. https://doi.org/10.1177/0146167211413125

Bishop, A. J., Martin, P., Poon, L., \& Johnson, M. A. (2011). Exploring Positive and Negative Affect as Key Indicators of Life Satisfaction among Centenarians: Does Cognitive 
663

664

665

666

667

668

669

670

671

672

673

674

675

676

677

678

679

680

681

682

683

684

685

Performance Matter? Journal of Aging Research, 2011, e953031.

https://doi.org/10.4061/2011/953031

Boone, J. E., Gordon-Larsen, P., Adair, L. S., \& Popkin, B. M. (2007). Screen time and physical activity during adolescence: longitudinal effects on obesity in young adulthood. International Journal of Behavioral Nutrition and Physical Activity, 4(1), 26. https://doi.org/10.1186/1479-5868-4-26

Brenning, K. M., Soenens, B., Braet, C., \& Bosmans, G. (2012). Attachment and depressive symptoms in middle childhood and early adolescence: Testing the validity of the emotion regulation model of attachment. Personal Relationships, 19(3), 445-464. https://doi.org/10.1111/j.1475-6811.2011.01372.x

Campbell, D. T., \& Fiske, D. W. (1959). Convergent and discriminant validation by the multitrait-multimethod matrix. Psychological Bulletin, 56(2), 81-105. https://doi.org/10.1037/h0046016

Charlton, J. P. (2002). A factor-analytic investigation of computer "addiction" and engagement. British Journal of Psychology, 93(3), 329-344. https://doi.org/10.1348/000712602760146242

Charlton, J. P., \& Danforth, I. D. W. (2007). Distinguishing addiction and high engagement in the context of online game playing. Computers in Human Behavior, 23(3), 1531-1548. https://doi.org/10.1016/j.chb.2005.07.002

Chen, B., Vansteenkiste, M., Beyers, W., Boone, L., Deci, E. L., Van der Kaap-Deeder, J., ... Verstuyf, J. (2015). Basic psychological need satisfaction, need frustration, and need strength across four cultures. Motivation and Emotion, 39(2), 216-236. https://doi.org/10.1007/s11031-014-9450-1 
686 Clancy, K., \& Gove, W. (1974). Sex Differences in Mental Illness: An Analysis of Response 687 Bias in Self-Reports. American Journal of Sociology, 80(1), 205-216. $688 \quad$ https://doi.org/10.2307/2776967

689 Clarke, A., Friede, T., Putz, R., Ashdown, J., Martin, S., Blake, A., ... others. (2011). Warwick690 Edinburgh Mental Well-being Scale (WEMWBS): validated for teenage school students in England and Scotland. A mixed methods assessment. BMC Public Health, 11(1), 487.

692 Cohen, S. (2004). Social Relationships and Health. American Psychologist, 59(8), 676-684.

693 https://doi.org/10.1037/0003-066X.59.8.676

694 Cohen, S., \& Hoberman, H. M. (1983). Positive Events and Social Supports as Buffers of Life 695 Change Stress1. Journal of Applied Social Psychology, 13(2), 99-125. https://doi.org/10.1111/j.1559-1816.1983.tb02325.x

697 Compas, B. E., Connor-Smith, J. K., Saltzman, H., Thomsen, A. H., \& Wadsworth, M. E. (2001). Coping with stress during childhood and adolescence: problems, progress, and 699 potential in theory and research. Psychological Bulletin, 127(1), 87-127.

700 Cranwell, J., Opazo-Breton, M., \& Britton, J. (2016). Adult and adolescent exposure to tobacco 701 and alcohol content in contemporary YouTube music videos in Great Britain: a population estimate. Journal of Epidemiology and Community Health, jech-2015-206402.

704 Cronbach, L. J., \& Meehl, P. E. (1955). Construct validity in psychological tests. Psychological 705 Bulletin, 52(4), 281-302. https://doi.org/10.1037/h0040957

706 Cumming, G. (2012). Understanding the new statistics: effect sizes, confidence intervals, and 707 meta-analysis. New York, NY: Routledge. 
708 Deci, E. L., \& Ryan, R. M. (2000). The "What" and "Why" of Goal Pursuits: Human Needs and

709 the Self-Determination of Behavior. Psychological Inquiry, 11(4), 227-268.

710 https://doi.org/10.1207/S15327965PLI1104_01

711 Deci, E. L., Ryan, R. M., Gagne, M., Leone, D. R., Usunov, J., \& Kornazheva, B. P. (2001).

712 Need Satisfaction, Motivation, and Well-Being in the Work Organizations of a Former

713 Eastern Bloc Country: A Cross-Cultural Study of Self-Determination. Personality and

714 Social Psychology Bulletin, 27(8), 930-942. https://doi.org/10.1177/0146167201278002

715 Desai, R. A., Krishnan-Sarin, S., Cavallo, D., \& Potenza, M. N. (2010). Video-Gaming Among

716 High School Students: Health Correlates, Gender Differences, and Problematic Gaming.

717 PEDIATRICS, 126(6), e1414-e1424. https://doi.org/10.1542/peds.2009-2706

718 Duggan, M. (2015a, December 15). Gaming and Gamers. Retrieved February 15, 2016, from

719 http://www.pewinternet.org/2015/12/15/gaming-and-gamers/

720 Duggan, M. (2015b, December 15). Who plays video games and identifies as a "gamer."

721 Retrieved April 13, 2016, from http://www.pewinternet.org/2015/12/15/who-plays-video-

722 games-and-identifies-as-a-gamer/

723 Faulkner, G., Irving, H., Adlaf, E. M., \& Turner, N. (2015). Subtypes of Adolescent Video

724 Gamers: a Latent Class Analysis. International Journal of Mental Health and Addiction,

725 13(1), 1-18. https://doi.org/10.1007/s11469-014-9501-6

726 Ferguson, C. J., Coulson, M., \& Barnett, J. (2011). A meta-analysis of pathological gaming

727 prevalence and comorbidity with mental health, academic and social problems. Journal

728 of Psychiatric Research, 45(12), 1573-1578. 
729 Festl, R., Scharkow, M., \& Quandt, T. (2013). Problematic computer game use among

$730 \quad$ adolescents, younger and older adults. Addiction, 108(3), 592-599.

$731 \quad$ https://doi.org/10.1111/add.12016

732 Finkel, S. E. (1995). Causal analysis with panel data. Thousand Oaks, Calif: Sage Publications.

733 Forest, J., Mageau, G. A., Sarrazin, C., \& Morin, E. M. (2011). "Work is my passion”: The different affective, behavioural, and cognitive consequences of harmonious and obsessive passion toward work. Canadian Journal of Administrative Sciences / Revue Canadienne

737

738

739

740

741

742

743

744

745

746

747

748

749

750

751 Des Sciences de l'Administration, 28(1), 27-40. https://doi.org/10.1002/cjas.170

Garnefski, N., Legerstee, J., Kraaij, V. V., Van Den Kommer, T., \& Teerds, J. (2002). Cognitive coping strategies and symptoms of depression and anxiety: a comparison between adolescents and adults. Journal of Adolescence, 25(6), 603-611.

Gentile, D. A., Choo, H., Liau, A., Sim, T., Li, D., Fung, D., \& Khoo, A. (2011). Pathological Video Game Use Among Youths: A Two-Year Longitudinal Study. PEDIATRICS, 127(2), e319-e329. https://doi.org/10.1542/peds.2010-1353

Granic, I., Lobel, A., \& Engels, R. C. M. E. (2014). The benefits of playing video games. American Psychologist, 69(1), 66-78. https://doi.org/10.1037/a0034857

Griffiths, M. D., van Rooij, A. J., Kardefelt-Winther, D., Starcevic, V., Király, O., Pallesen, S., ... Demetrovics, Z. (2016). Working towards an international consensus on criteria for assessing internet gaming disorder: a critical commentary on Petry et al . (2014): Assessment of internet gaming disorder. Addiction, 111(1), 167-175. https://doi.org/10.1111/add.13057

Hasin, D. S., O’Brien, C. P., Auriacombe, M., Borges, G., Bucholz, K., Budney, A., ... Grant, B. F. (2013). DSM-5 Criteria for Substance Use Disorders: Recommendations and 
752

753

754

755

756

757

758

759

760

761

762

763

764

765

766

767

768

769

770

771

772

773

774

Rationale. The American Journal of Psychiatry, 170(8), 834-851. https://doi.org/10.1176/appi.ajp.2013.12060782

Hodgins, D. C., Peden, N., \& Cassidy, E. (2005). The Association Between Comorbidity and Outcome in Pathological Gambling: A Prospective Follow-up of Recent Quitters. Journal of Gambling Studies, 21(3), 255-271. https://doi.org/10.1007/s10899-005-3099-3

Hodgins, H. S., Koestner, R., \& Duncan, N. (1996). On the Compatibility of Autonomy and Relatedness. Personality and Social Psychology Bulletin, 22(3), 227-237. https://doi.org/10.1177/0146167296223001

Hofferth, S. L., \& Moon, U. J. (2012). Electronic Play, Study, Communication, and Adolescent Achievement, 2003-2008. Journal of Research on Adolescence, 22(2), 215-224. https://doi.org/10.1111/j.1532-7795.2011.00770.x

House, J., Landis, K., \& Umberson, D. (1988). Social relationships and health. Science, 241(4865), 540-545. https://doi.org/10.1126/science.3399889

Ioannidis, J. P. A. (2012). Why Science Is Not Necessarily Self-Correcting. Perspectives on Psychological Science, 7(6), 645-654. https://doi.org/10.1177/1745691612464056

Jeličić, H., Phelps, E., \& Lerner, R. M. (2009). Use of missing data methods in longitudinal studies: The persistence of bad practices in developmental psychology. Developmental Psychology, 45(4), 1195-1199. https://doi.org/10.1037/a0015665

Kardefelt-Winther, D. (2014a). A conceptual and methodological critique of internet addiction research: Towards a model of compensatory internet use. Computers in Human Behavior, 31, 351-354. https://doi.org/10.1016/j.chb.2013.10.059

Kardefelt-Winther, D. (2014b). Meeting the unique challenges of assessing internet gaming disorder. Addiction, 109(9), 1568-1570. https://doi.org/10.1111/add.12645 
775 King, D. L., Haagsma, M. C., Delfabbro, P. H., Gradisar, M., \& Griffiths, M. D. (2013). Toward

776

777

778

779

780

781

782

783

784

785

786

787

788

789

790

791

792

793

794

795 a consensus definition of pathological video-gaming: A systematic review of psychometric assessment tools. Clinical Psychology Review. Retrieved from http://www.sciencedirect.com/science/article/pii/S0272735813000056

Kraut, R., Patterson, M., Lundmark, V., Kiesler, S., Mukopadhyay, T., \& Scherlis, W. (1998). Internet paradox. A social technology that reduces social involvement and psychological well-being? The American Psychologist, 53(9), 1017-1031.

Kremer, P., Elshaug, C., Leslie, E., Toumbourou, J. W., Patton, G. C., \& Williams, J. (2014). Physical activity, leisure-time screen use and depression among children and young adolescents. Journal of Science and Medicine in Sport, 17(2), 183-187. https://doi.org/10.1016/j.jsams.2013.03.012

La Guardia, J. G., Ryan, R. M., Couchman, C. E., \& Deci, E. L. (2000). Within-person variation in security of attachment: A self-determination theory perspective on attachment, need fulfillment, and well-being. Journal of Personality and Social Psychology, 79(3), 367384. https://doi.org/10.1037/0022-3514.79.3.367

Lafrenière, M.-A. K., Verner-Filion, J., \& Vallerand, R. J. (2012). Development and validation of the Gaming Motivation Scale (GAMS). Personality and Individual Differences, 53(7), 827-831. https://doi.org/10.1016/j.paid.2012.06.013

Laganà, L., Bratly, M. L., \& Boutakidis, I. (2011). The validation of a new measure quantifying the social quality of life of ethnically diverse older women: two cross-sectional studies. BMC Geriatrics, 11(1). https://doi.org/10.1186/1471-2318-11-60 
796 Lalande, D., Vallerand, R. J., Lafrenière, M.-A. K., Verner-Filion, J., Laurent, F.-A., Forest, J.,

797 \& Paquet, Y. (2015). Obsessive Passion: A Compensatory Response to Unsatisfied

798 Needs. Journal of Personality, n/a-n/a. https://doi.org/10.1111/jopy.12229

799 Lanningham-Foster, L., Jensen, T. B., Foster, R. C., Redmond, A. B., Walker, B. A., Heinz, D., 800 \& Levine, J. A. (2006). Energy Expenditure of Sedentary Screen Time Compared With 801 Active Screen Time for Children. PEDIATRICS, 118(6), e1831-e1835.

802 https://doi.org/10.1542/peds.2006-1087

803 Legate, N., DeHaan, C. R., Weinstein, N., \& Ryan, R. M. (2013). Hurting You Hurts Me Too:

804 The Psychological Costs of Complying With Ostracism. Psychological Science, 24(4), 805 583-588. https://doi.org/10.1177/0956797612457951

806 Lenhart, A. (2015, August 6). Teens, Technology and Friendships. Retrieved February 23, 2016, 807 from http://www.pewinternet.org/2015/08/06/teens-technology-and-friendships/

808 Little, T. D., Preacher, K. J., Selig, J. P., \& Card, N. A. (2007). New developments in latent $809 \quad$ variable panel analyses of longitudinal data. International Journal of Behavioral 810 Development, 31(4), 357-365. https://doi.org/10.1177/0165025407077757

811 Luyten, P., \& Blatt, S. J. (2013). Interpersonal relatedness and self-definition in normal and 812 disrupted personality development: Retrospect and prospect. American Psychologist, 813 68(3), 172-183. https://doi.org/10.1037/a0032243

814 Marsh, H. W., Pekrun, R., Lichtenfeld, S., Guo, J., Arens, A. K., \& Murayama, K. (2016).

815 Breaking the double-edged sword of effort/trying hard: Developmental equilibrium and 816 longitudinal relations among effort, achievement, and academic self-concept.

817 Developmental Psychology, 52(8), 1273-1290. https://doi.org/10.1037/dev0000146 
818 Mellor, D., Stokes, M., Firth, L., Hayashi, Y., \& Cummins, R. (2008). Need for belonging,

819 relationship satisfaction, loneliness, and life satisfaction. Personality and Individual

820 Differences, 45(3), 213-218. https://doi.org/10.1016/j.paid.2008.03.020

821 Menard, S. W. (2002). Longitudinal research (2nd ed). Thousand Oaks, Calif: Sage Publications.

822 Meng, Z., Liu, C., Yu, C., \& Ma, Y. (2014). Transcranial direct current stimulation of the

823 frontal-parietal-temporal area attenuates smoking behavior. Journal of Psychiatric

824 Research, 54, 19-25. https://doi.org/10.1016/j.jpsychires.2014.03.007

825 Mentzoni, R. A., Brunborg, G. S., Molde, H., Myrseth, H., Skouverøe, K. J. M., Hetland, J., \&

826 Pallesen, S. (2011). Problematic video game use: estimated prevalence and associations

827 with mental and physical health. Cyberpsychology, Behavior and Social Networking,

828 14(10), 591-596. https://doi.org/10.1089/cyber.2010.0260

829 Milton, K., Bull, F. C., \& Bauman, A. (2011). Reliability and validity testing of a single-item

$830 \quad$ physical activity measure. British Journal of Sports Medicine, 45(3), 203-208.

831 https://doi.org/10.1136/bjsm.2009.068395

832 Moller, A. C., \& Deci, E. L. (2010). Interpersonal control, dehumanization, and violence: A self-

833 determination theory perspective. Group Processes \& Intergroup Relations, 13(1), 41-

834 53. https://doi.org/10.1177/1368430209350318

835 Morey, R. D., Chambers, C. D., Etchells, P. J., Harris, C. R., Hoekstra, R., Lakens, D., ...

836 Zwaan, R. A. (2016). The Peer Reviewers' Openness Initiative: incentivizing open

837 research practices through peer review. Royal Society Open Science, 3(1), 150547.

838 https://doi.org/10.1098/rsos.150547

839 MPAA. (2015). Theatric Market Statistics 2015. Retrieved from http://www.mpaa.org/wp-

840 content/uploads/2016/04/MPAA-Theatrical-Market-Statistics-2015_Final.pdf 
841 Murphy, P., \& Schachar, R. (2000). Use of self-ratings in the assessment of symptoms of

842 attention deficit hyperactivity disorder in adults. The American Journal of Psychiatry, 843 157(7), 1156-1159. https://doi.org/10.1176/appi.ajp.157.7.1156

844 Neuman, S. B. (1988). The Displacement Effect: Assessing the Relation between Television 845 Viewing and Reading Performance. Reading Research Quarterly, 23(4), 414-440.

846 https://doi.org/10.2307/747641

847 Newzoo. (2016). The Global Games Market: Key Facts \& Insights On the Global Games Market 848 2012-2016. Retrieved from https://newzoo.com/wp-

849 content/uploads/2011/06/Newzoo_Free_Global_Trend_Report_2012_2016_V2.pdf

850 Ng, B. D., \& Wiemer-Hastings, P. (2005). Addiction to the internet and online gaming.

851 Cyberpsychology \& Behavior: The Impact of the Internet, Multimedia and Virtual Reality

852 on Behavior and Society, 8(2), 110-113. https://doi.org/10.1089/cpb.2005.8.110

853 Ng, J. Y. Y., Ntoumanis, N., Thogersen-Ntoumani, C., Deci, E. L., Ryan, R. M., Duda, J. L., \& 854 Williams, G. C. (2012). Self-Determination Theory Applied to Health Contexts: A MetaAnalysis. Perspectives on Psychological Science, 7(4), 325-340. https://doi.org/10.1177/1745691612447309

Nguyen-Rodriguez, S. T., Unger, J. B., \& Spruijt-Metz, D. (2009). Psychological Determinants of Emotional Eating in Adolescence. Eating Disorders, 17(3), 211-224.

860 Niemiec, C. P., Ryan, R. M., \& Deci, E. L. (2009). The path taken: Consequences of attaining 861 intrinsic and extrinsic aspirations in post-college life. Journal of Research in Personality, 862 43(3), 291-306. https://doi.org/10.1016/j.jrp.2008.09.001 
863 Parkes, A., Sweeting, H., Wight, D., \& Henderson, M. (2013). Do television and electronic

864 games predict children's psychosocial adjustment? Longitudinal research using the UK

865 Millennium Cohort Study. Archives of Disease in Childhood, archdischild-2011-301508.

866 https://doi.org/10.1136/archdischild-2011-301508

867 Patrick, H., Knee, C. R., Canevello, A., \& Lonsbary, C. (2007). The role of need fulfillment in

868 relationship functioning and well-being: A self-determination theory perspective. Journal

869 of Personality and Social Psychology, 92(3), 434-457. https://doi.org/10.1037/0022-

$870 \quad 3514.92 .3 .434$

871 Peters, C. S., \& Malesky, L. A. (2008). Problematic Usage Among Highly-Engaged Players of

872 Massively Multiplayer Online Role Playing Games. CyberPsychology \& Behavior, 11(4),

873 481-484. https://doi.org/10.1089/cpb.2007.0140

874 Petry, N. M., Rehbein, F., Gentile, D. A., Lemmens, J. S., Rumpf, H.-J., Mößle, T., ... O’Brien, C. P. (2014). An international consensus for assessing internet gaming disorder using the new DSM-5 approach: Internet gaming disorder. Addiction, 109(9), 1399-1406. https://doi.org/10.1111/add.12457

878

Pontes, H. M., Király, O., Demetrovics, Z., \& Griffiths, M. D. (2014). The Conceptualisation and 879 Measurement of DSM-5 Internet Gaming Disorder: The Development of the IGD-20

880 Test. PLOS ONE, 9(10), e110137. https://doi.org/10.1371/journal.pone.0110137

881 Przybylski, A. K. (2016). Mischievous responding in Internet Gaming Disorder research. PeerJ, 882 4, e2401. https://doi.org/10.7717/peerj.2401

883 Przybylski, A. K., Deci, E. L., Rigby, C. S., \& Ryan, R. M. (2014). Competence-impeding 884 electronic games and players' aggressive feelings, thoughts, and behaviors. Journal of 885 Personality and Social Psychology, 106(3), 441-457. https://doi.org/10.1037/a0034820 
886 Przybylski, A. K., Rigby, C. S., \& Ryan, R. M. (2010). A motivational model of video game 887 engagement. Review of General Psychology, 14(2), 154-166.

$888 \quad$ https://doi.org/10.1037/a0019440

889 Przybylski, A. K., Weinstein, N., \& Murayama, K. (2016a). Internet Gaming Disorder:

890 Investigating the Clinical Relevance of a New Phenomenon. American Journal of

$891 \quad$ Psychiatry. https://doi.org/10.1176/appi.ajp.2016.16020224

892 Przybylski, A. K., Weinstein, N., \& Murayama, K. (2016b). Registration Fork of Prospective 893 Study of Internet Gaming Disorder in a U.S. Cohort. Retrieved April 10, 2017, from 894 https://osf.io/ngy7j/?view_only=0ac76c77c95e4d4ebb07bd51bfd1e82c

895 Przybylski, A. K., Weinstein, N., \& Murayama, K. (2017). Prospective Study of Internet Gaming 896 Disorder in a U.S. Cohort. Retrieved April 10, 2017, from https://osf.io/ge9tp/?view_only=ad9dbeb3fc744c40a3e007750aef2fef

898 Przybylski, A. K., Weinstein, N., Ryan, R. M., \& Rigby, C. S. (2009). Having to versus Wanting 899 to Play: Background and Consequences of Harmonious versus Obsessive Engagement in

900 Video Games. CyberPsychology \& Behavior, 12(5), 485-492.

901 https://doi.org/10.1089/cpb.2009.0083

902 Reeves, S., Halsey, L. G., McMeel, Y., \& Huber, J. W. (2013). Breakfast habits, beliefs and 903 measures of health and wellbeing in a nationally representative UK sample. Appetite, 60, 904 51-57. https://doi.org/10.1016/j.appet.2012.09.024

905

Reinboth, M., Duda, J. L., \& Ntoumanis, N. (2004). Dimensions of Coaching Behavior, Need 906 Satisfaction, and the Psychological and Physical Welfare of Young Athletes. Motivation and Emotion, 28(3), 297-313. https://doi.org/10.1023/B:MOEM.0000040156.81924.b8 
908 Rosseel, Y. (2012). lavaan: An R Package for Structural Equation Modeling. Journal of 909 Statistical Software, 48(2). https://doi.org/10.18637/jss.v048.i02

910 Roth, G., \& Assor, A. (2012). The costs of parental pressure to express emotions: Conditional 911 regard and autonomy support as predictors of emotion regulation and intimacy. Journal 912 of Adolescence, 35(4), 799-808. https://doi.org/10.1016/j.adolescence.2011.11.005

913 Roth, G., Assor, A., Niemiec, C. P., Ryan, R. M., \& Deci, E. L. (2009). The emotional and 914 academic consequences of parental conditional regard: Comparing conditional positive 915 regard, conditional negative regard, and autonomy support as parenting practices. 916 Developmental Psychology, 45(4), 1119-1142. https://doi.org/10.1037/a0015272

917 Ryan, R. M. (2005). The developmental line of autonomy in the etiology, dynamics, and 918 treatment of borderline personality disorders. Development and Psychopathology, 17(4). https://doi.org/10.1017/S0954579405050467

920 Ryan, R. M., \& Deci, E. L. (2000). Self-determination theory and the facilitation of intrinsic 921 motivation, social development, and well-being. American Psychologist, 55(1), 68-78.

922 https://doi.org/10.1037/0003-066X.55.1.68

923 Ryan, R. M., \& Deci, E. L. (2001). On Happiness and Human Potentials: A Review of Research 924 925 on Hedonic and Eudaimonic Well-Being. Annual Review of Psychology, 52(1), 141-166.

926 Ryan, R. M., \& Deci, E. L. (2017). Self-determination theory: basic psychological needs in 927 motivation, development, and wellness. New York: Guilford Press.

928 Saitz, R., Larson, M. J., LaBelle, C., Richardson, J., \& Samet, J. H. (2008). The Case for Chronic 929 Disease Management for Addiction: Journal of Addiction Medicine, 2(2), 55-65. https://doi.org/10.1097/ADM.0b013e318166af74 
931 Salkovskis, P. M., Rimes, K. A., Warwick, H. M. C., \& Clark, D. M. (2002). The Health Anxiety

932 Inventory: development and validation of scales for the measurement of health anxiety

933 and hypochondriasis. Psychological Medicine, 32(5).

934 https://doi.org/10.1017/S0033291702005822

935 Scharkow, M., Festl, R., \& Quandt, T. (2014). Longitudinal patterns of problematic computer 936 game use among adolescents and adults-a 2-year panel study: Longitudinal patterns of 937 problematic gaming. Addiction, 109(11), 1910-1917. https://doi.org/10.1111/add.12662

938 Seeman, T. E. (1996). Social ties and health: the benefits of social integration. Annals of $939 \quad$ Epidemiology, 6(5), 442-451.

940 Sheldon, K. M., Abad, N., \& Hinsch, C. (2011). A two-process view of Facebook use and 941 relatedness need-satisfaction: Disconnection drives use, and connection rewards it. 942 Psychology of Popular Media Culture, 1(S), 2-15. https://doi.org/10.1037/2160-

943 4134.1.S.2

944 Sheldon, K. M., Ryan, R., \& Reis, H. T. (1996). What Makes for a Good Day? Competence and 945 946 Autonomy in the Day and in the Person. Personality and Social Psychology Bulletin, 22(12), 1270-1279. https://doi.org/10.1177/01461672962212007

947

Shen, Y., Cao, X., Tan, T., Shan, C., Wang, Y., Pan, J., ... Yuan, T.-F. (2016). 10-Hz Repetitive 948 Transcranial Magnetic Stimulation of the Left Dorsolateral Prefrontal Cortex Reduces Heroin Cue Craving in Long-Term Addicts. Biological Psychiatry, 80(3), e13-14.

950 https://doi.org/10.1016/j.biopsych.2016.02.006

951 Sherbourne, C. D., \& Stewart, A. L. (1991). The MOS social support survey. Social Science \& 952 Medicine, 32(6), 705-714. https://doi.org/10.1016/0277-9536(91)90150-B 
953 Sisson, S. B., Broyles, S. T., Baker, B. L., \& Katzmarzyk, P. T. (2010). Screen Time, Physical

954 Activity, and Overweight in U.S. Youth: National Survey of Children's Health 2003.

955 Journal of Adolescent Health, 47(3), 309-311.

956 https://doi.org/10.1016/j.jadohealth.2010.02.016

957

958

959

960

961

962

963

964

965

966

967

968

969

970

971

972

973

974

975

Slutske, W. S., Jackson, K. M., \& Sher, K. J. (2003). The natural history of problem gambling from age 18 to 29. Journal of Abnormal Psychology, 112(2), 263-274. https://doi.org/10.1037/0021-843X.112.2.263

Soenens, B., Park, S.-Y., Vansteenkiste, M., \& Mouratidis, A. (2012). Perceived parental psychological control and adolescent depressive experiences: A cross-cultural study with Belgian and South-Korean adolescents. Journal of Adolescence, 35(2), 261-272. https://doi.org/10.1016/j.adolescence.2011.05.001

Steel, Z., \& Blaszczynski, A. (1998). Impulsivity, personality disorders and pathological gambling severity. Addiction, 93(6), 895-905. https://doi.org/10.1046/j.13600443.1998.93689511.x

Talley, A., Molix, L., Schlegel, R. J., \& Bettencourt, A. (2010). The influence of breast cancer survivors' Perceived partner social support and need satisfaction on depressive symptoms: A longitudinal analysis. Psychology \& Health, 25(4), 433-449. https://doi.org/10.1080/08870440802582682

Terraneo, A., Leggio, L., Saladini, M., Ermani, M., Bonci, A., \& Gallimberti, L. (2016). Transcranial magnetic stimulation of dorsolateral prefrontal cortex reduces cocaine use: A pilot study. European Neuropsychopharmacology: The Journal of the European College of Neuropsychopharmacology, 26(1), 37-44. https://doi.org/10.1016/j.euroneuro.2015.11.011 
976 Thompson, C. A., \& Prottas, D. J. (2006). Relationships among organizational family support, 977 job autonomy, perceived control, and employee well-being. Journal of Occupational 978 Health Psychology, 11(1), 100-118. https://doi.org/10.1037/1076-8998.10.4.100

979 Valkenburg, P. M., \& Peter, J. (2009). Social Consequences of the Internet for Adolescents: A 980 Decade of Research. Current Directions in Psychological Science, 18(1), 1-5.

$981 \quad$ https://doi.org/10.1111/j.1467-8721.2009.01595.x

982 Van den Broeck, A., Vansteenkiste, M., De Witte, H., \& Lens, W. (2008). Explaining the 983 relationships between job characteristics, burnout, and engagement: The role of basic 984 psychological need satisfaction. Work \& Stress, 22(3), 277-294.

985 https://doi.org/10.1080/02678370802393672

986 Verstuyf, J., Patrick, H., Vansteenkiste, M., \& Teixeira, P. J. (2012). Motivational dynamics of 987 eating regulation: a self-determination theory perspective. International Journal of Behavioral Nutrition and Physical Activity, 9(1), 21. https://doi.org/10.1186/1479-5868$9-21$

Wagenmakers, E.-J., Wetzels, R., Borsboom, D., Maas, H. L. J. van der, \& Kievit, R. A. (2012). An Agenda for Purely Confirmatory Research. Perspectives on Psychological Science, 7(6), 632-638. https://doi.org/10.1177/1745691612463078

Ware, J. E., \& Sherbourne, C. D. (1992). The MOS 36-Item Short-Form Health Survey (SF-36): I. Conceptual Framework and Item Selection. Medical Care, 30(6), 473-483.

Wei, M., Shaffer, P. A., Young, S. K., \& Zakalik, R. A. (2005). Adult Attachment, Shame, Depression, and Loneliness: The Mediation Role of Basic Psychological Needs Satisfaction. Journal of Counseling Psychology, 52(4), 591-601. https://doi.org/10.1037/0022-0167.52.4.591 
999 Weinstein, N. (2009). Interest-taking and carry-over effects of incidental rejection emotions.

$1000 \quad$ Retrieved from

1001 https://urresearch.rochester.edu/institutionalPublicationPublicView.action;jsessionid=7F3

1002 66375DEC84A0593CFEF4209FF31AC?institutionalItemId=9139

1003 Weinstein, N., Hodgins, H. S., \& Ostvik-White, E. (2011). Humor as aggression: Effects of

1004 motivation on hostility expressed in humor appreciation. Journal of Personality and

1005 Social Psychology, 100(6), 1043-1055. https://doi.org/10.1037/a0022495

1006 Weinstein, N., \& Ryan, R. M. (2010). When helping helps: Autonomous motivation for prosocial

1007 behavior and its influence on well-being for the helper and recipient. Journal of

1008 Personality and Social Psychology, 98(2), 222-244. https://doi.org/10.1037/a0016984

1009 Weiss, R. D., Najavits, L. M., Greenfield, S. F., Soto, J. A., Shaw, S. R., \& Wyner, D. (1998).

$1010 \quad$ Validity of substance use self-reports in dually diagnosed outpatients. The American

1011 Journal of Psychiatry, 155(1), 127-128. https://doi.org/10.1176/ajp.155.1.127

1012 Wheeler, L., \& Reis, H. T. (1991). Self-Recording of Everyday Life Events: Origins, Types, and

1013 Uses. Journal of Personality, 59(3), 339-354. https://doi.org/10.1111/j.1467-

1014 6494.1991.tb00252.x

1015 Widyanto, L., \& McMurran, M. (2004). The Psychometric Properties of the Internet Addiction

1016 Test. CyberPsychology \& Behavior, 7(4), 443-450.

1017 https://doi.org/10.1089/cpb.2004.7.443

1018 Williams, G. C., Hedberg, V. A., Cox, E. M., \& Deci, E. L. (2000). Extrinsic Life Goals and 1019 Health-Risk Behaviors in Adolescents1. Journal of Applied Social Psychology, 30(8), 1020 1756-1771. https://doi.org/10.1111/j.1559-1816.2000.tb02466.x 
1021 Wilson, P. M., Rodgers, W. M., Blanchard, C. M., \& Gessell, J. (2003). The Relationship

1022 Between Psychological Needs, Self-Determined Motivation, Exercise Attitudes, and

1023 Physical Fitness1. Journal of Applied Social Psychology, 33(11), 2373-2392.

1024 https://doi.org/10.1111/j.1559-1816.2003.tb01890.x

1025 YouGov. (2017a). Terms \& Conditions Combined. Retrieved July 3, 2017, from

1026 https://yougov.co.uk/about/terms-combined/\#/terms

1027 YouGov. (2017b). YouGov Privacy Policy. Retrieved July 3, 2017, from

1028 https://yougov.co.uk/about/terms-combined/\#/privacy

1029

1030 


\section{Table 1 (on next page)}

Summary of study hypotheses and exploratory analyses. 
1

\begin{tabular}{lllll}
\hline & Time 1 Variables & Influence & Time 2 Variables \\
\hline Confirmatory & 1. & IGD & Direct Positive on & IGD \\
Hypotheses & 2. & Need Supports & Direct Positive on & Need Supports \\
& 3. & Health & Direct Positive on & Health \\
& 4. & Need Supports & Direct Negative on & IGD \\
& 5. & IGD & Direct Negative on & Need Supports \\
& 6. & Need Supports & Direct Positive on & Health \\
7. & IGD & Direct Negative on & Health \\
Analyses & 1. & Need Supports & Mediate the Negative effect of IGD on & Health \\
& 2. & Competence & Mediate the Negative effect of IGD on & Health \\
& 3. & Relatedness & Mediate the Negative effect of IGD on & Health \\
& 4. & Autonomy & Mediate the Negative effect of IGD on & Health \\
& 5. & Physical Activity & Direct Positive on & Health \\
& 6. & Social Activity & Direct Positive on & Health \\
& 7. & Physical Activity & Mediate the Negative effect of IGD on & Health \\
& 8. & Social Activity & Mediate the Negative effect of IGD on & Health \\
\hline
\end{tabular}

2

3 


\section{Table 2 (on next page)}

Indirect effects of Internet Gaming Disorder on health as mediated by basic psychological need supports.

Note. All path coefficients are statistically significant at the $p<.05$ level. All coefficients are represented by unstandardized slopes. Our preference was to report standardized coefficients but it is difficult to precisely estimate the confidence interval of standardized indirect effects (Cohen, Cohen, West, \& Aiken, 2013). 
1

\begin{tabular}{|c|c|c|c|c|c|c|}
\hline & \multicolumn{2}{|c|}{$\begin{array}{c}\text { IGD to } \\
\text { Need Satisfaction }\end{array}$} & \multicolumn{2}{|c|}{$\begin{array}{l}\text { Need Satisfaction } \\
\text { to health }\end{array}$} & \multicolumn{2}{|c|}{ Indirect effect } \\
\hline & $b$ & $95 \% \mathrm{CI}$ & $b$ & $95 \% \mathrm{CI}$ & $b$ & $95 \% \mathrm{CI}$ \\
\hline Psychological Need Satisfaction & -0.06 & $-0.09,-0.03$ & 0.07 & $0.04,0.10$ & -0.004 & $-0.007,-0.002$ \\
\hline Autonomy Need Satisfaction & -0.07 & $-0.11,-0.03$ & 0.05 & $0.02,0.07$ & -0.003 & $-0.006,-0.001$ \\
\hline Competence Need Satisfaction & -0.06 & $-0.09,-0.02$ & 0.06 & $0.02,0.07$ & -0.003 & $-0.005,-0.000$ \\
\hline Relatedness Need Satisfaction & -0.06 & $-0.10,-0.03$ & 0.05 & $0.03,0.08$ & -0.003 & $-0.006,-0.001$ \\
\hline
\end{tabular}
2

3 


\section{Figure 1 (on next page)}

Two-wave model testing cross-lagged effects of IGD, basic psychological need satisfaction and health.

Note. H1-H7 Denotes Hypotheses 1 through 7. Nested models include covariances between measures at baseline and six-month follow-up. 


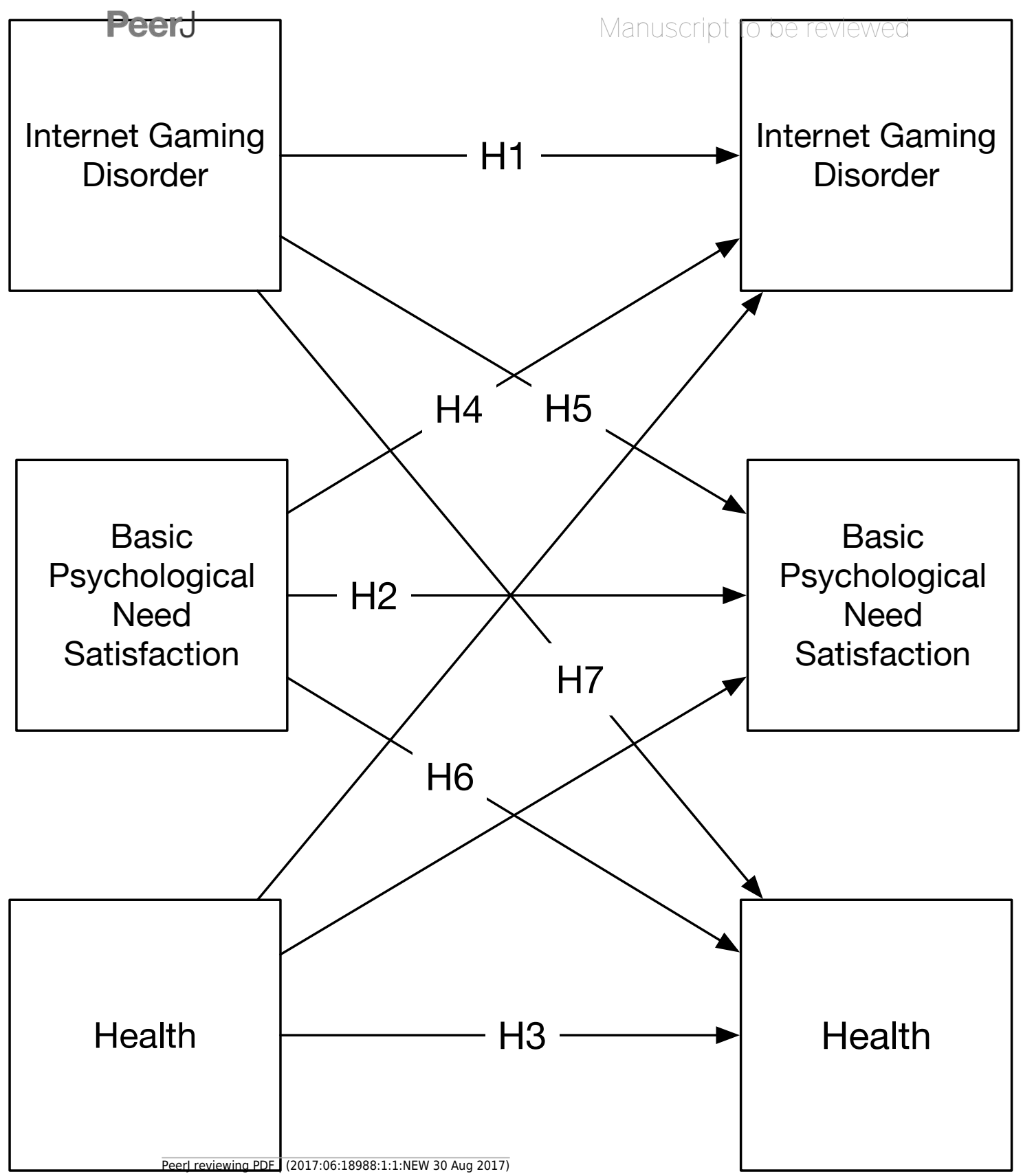




\section{Figure 2 (on next page)}

Exploratory two-wave models testing cross-lagged effects of IGD, basic psychological need satisfaction, health, and social and physical activity.

Note. Separate models examined social and physical activity. Tested models include covarainces, between measures at baseline and at six-month follow-up. 


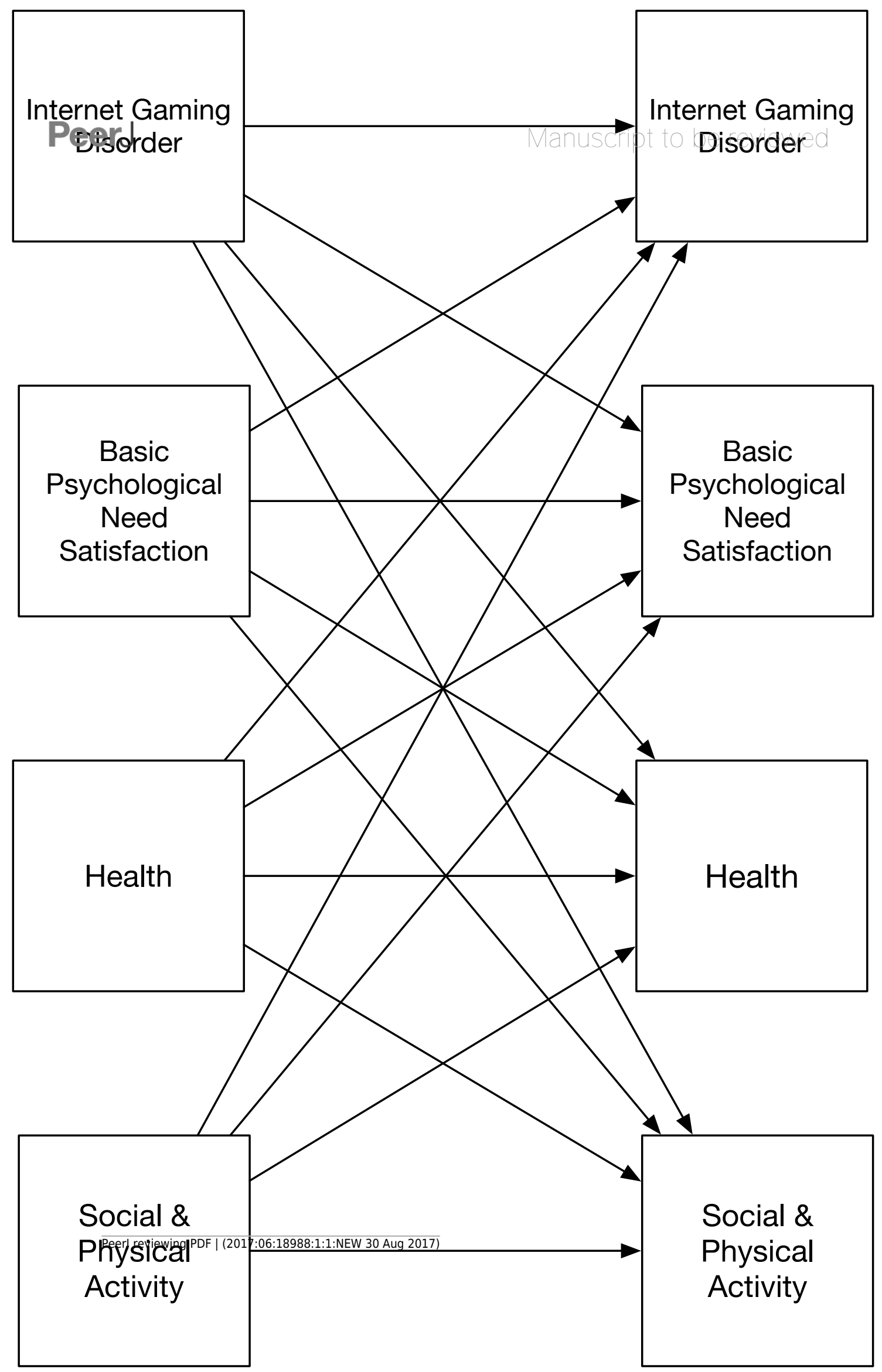




\section{Figure 3 (on next page)}

Confirmatory two-wave model showing standardised effects of IGD, basic psychological need satisfaction, and health.

Note. H1-H7 Denotes Hypotheses 1 through 7. Nested models include covariances between measures at baseline and six-month follow-up. 
